\title{
FLORA DE GRÃO-MOGOL, MINAS GERAIS: SCROPHULARIACEAE ${ }^{1}$
}

\author{
VINÍCIUS CASTRO SOUZA \& JULIANA DE PAULA SOUZA
}

Herbário ESA, Departamento de Ciências Biológicas, Escola Superior de Agricultura Luiz de Queiroz, Universidade de São Paulo, Caixa Postal 9, 13418-900 - Piracicaba, SP, Brasil.

Barroso, G.M. 1952. Scrophulariaceae indígenas e exóticas do Brasil. Rodriguésia 15 (27): 9-64.

Schмidt, J.A. 1862. Scrophularinae. In C.F.P. Martius, A.G. Eichler \& I. Urban (eds.) Flora brasiliensis. Frid. Fleischer. Leipzig, vol. 8, pars 1, p. 230-340, tab. 39-57.

SouzA, V.C. 1996. Levantamento das espécies de Scrophulariaceae nativas do Brasil. Tese de Doutorado. Instituto de Biociências, Universidade de São Paulo. São Paulo.

SouzA, V.C. 1995. Scrophulariaceae. In B.L. Stannard (ed.) Flora of the Pico das Almas, Chapada Diamantina, Bahia, Brazil. Royal Botanic Gardens, Kew, p. 586-593.

SouzA, V.C. 2003. Scrophulariaceae. In M.G.L. Wanderley, G.J. Shepherd, T.S. Melhem, A.M. Giulietti \& M. Kirizawa (eds.) Flora fanerogâmica do Estado de São Paulo. FAPESP, RiMa. São Paulo, vol. 3, p. 297-321.

1. Sépalas unidas..

2. Flores pediceladas, anteras bitecas

Physocalyx aurantiacus

2'. Flores sésseis, anteras monotecas Buchnera

3. Folhas uninérveas B. palustris

3'. Folhas 3-5 nérveas B. lavandulacea

$1 '$. Sépalas livres.

4. Anteras com conectivo muito desenvolvido, mantendo as tecas separadas.

5. Cálice com sépalas externas muito mais largas que as internas

5'. Cálice com sépalas iguais ou subiguais entre si

Mecardonia serpylloides

6. Ervas eretas a arbustos; base da folha aguda a atenuada Stemodia

6 '. Ervas prostradas; base da folha truncada a obtusa S. pratensis

4'. Anteras com conectivo pouco desenvolvido.

7. Corola rotácea S. microphylla

7'. Corola globosa, bigibosa na porção ventral Scoparia dulcis

8. Caule glabro ou com tricomas apenas na região dos nós foliares; sépalas glabras; corola provida de apêndice na fauce Angelonia

8'. Caule com indumento pubescente ao menos na região florífera; sépalas densamente

ferrugíneo-pubescentes; apêndice da corola ausente

A. goyazensis A. eriostachys

\section{Angelonia Bonpl.}

Ervas ou subarbustos, raramente arbustos, glabros, pubescentes ou tomentosos. Folhas opostas, raramente alternas ou verticiladas, sésseis a subsésseis, raramente pecioladas, com formato e margem bastante variáveis. Flores axilares, solitárias ou geminadas, freqüentemente concentradas nas terminações dos ramos formando um racemo bem definido ou não, pediceladas; bractéolas presentes ou ausentes; cálice pentâmero, dialissépalo, com sépalas iguais entre si; corola geralmente roxa ou lilás, menos freqüentemente alva ou azul, globosa, bigibosa na porção ventral, freqüentemente com um apêndice inserido na fauce; estames 4, inclusos, inseridos no tubo da corola, anteras com tecas divergentes; ovário pluriovulado. Fruto cápsula loculicida ou seco indeiscente. Sementes geralmente trigonais, com testa cristado-reticulada.

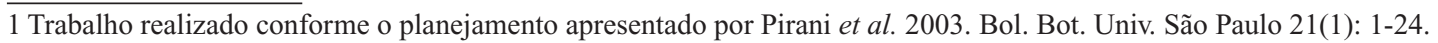


1.1. Angelonia eriostachys Benth. in DC., Prodr. 10: 254. 1846.

Ervas 40-150 cm alt.; ramos glabros, ferrugíneo-pubescentes apenas na região florífera; internós 1,8-6 cm compr. Folhas opostas ou verticiladas, sésseis ou com pecíolo até $0,2(0,3) \mathrm{cm}$ compr., elípticas ou oblanceoladas, 2,7-6,6 cm compr., 0,5-2,1(2,7) cm larg., ápice agudo, margem inteira, freqüentemente revoluta, base atenuada, glabras em ambas as faces. Flores em racemos; pedicelo 1,2-1,8 cm compr., ferrugíneo-pubescente; brácteas lanceoladas ou elípticas, 0,6-0,8 cm compr., 0,15-0,2 cm larg., ápice agudo, glabras, tornando-se densamente pubescentes em direção ao ápice do racemo. Sépalas elípticas ou lanceoladas, 0,5-0,8 cm compr., 0,15-0,3 cm larg., ápice agudo, ferrugíneo-pubescentes; corola roxa com pontuações vináceas no interior do tubo, apêndice ausente, gibas arredondadas, tubo 1,0 cm compr., lobos orbiculares, 0,70,9 cm compr. Cápsula ovóide, 1,0-1,3 cm compr., 0,9-1,1 cm diâm. (Fig. 1. A-B)

Campos et al. CFCR 13442 (ESA, SPF); Pirani \& Mello-Silva CFCR 10780 (ESA, SPF); Zappi CFCR 13036 (SPF).

Ocorre nos campos rupestres da Cadeia do Espinhaço em Minas Gerais. Em Grão-Mogol ocorre em campos rupestres com afloramentos de rocha quartzítica com solo arenoso semi-úmido, graminoso. Foi coletada em flor nos meses de maio, junho e setembro.

1.2. Angelonia goyazensis Benth. in DC., Prodr. 10: 253. 1846.

Erva 30-75 cm alt.; ramos glabros; internós 1,2-3,8 cm compr. Folhas opostas, sésseis ou com pecíolo até $1 \mathrm{~mm}$ compr., elípticas ou oblanceoladas, 1,5-3,9 cm compr., 0,6-1,6 cm larg., ápice agudo, margem serreada, base atenuada, glabras em ambas as faces, ciliadas na base junto à inserção. Flores axilares, solitárias, concentradas nas terminações dos ramos, formando um racemo não bem definido; pedicelo 0,5-0,6 cm compr., pubérulo. Sépalas lanceoladas, 0,25-0,3 cm compr., 0,1 cm larg., ápice acuminado, glabras; corola violeta ou roxa com tubo e gibas esverdeadas ou amarelas, tubo 0,6-0,7 cm compr., apêndice linear com ápice bífido, gibas arredondadas, lobos obovais, 0,4 cm compr. Cápsula globosa, 0,6-1,0 cm diâm. (Fig. 1. C-D)

Barreto et al. CFCR 12036 (ESA, SPF); Esteves et al. CFCR 13247 (ESA, SPF); Oliveira et al. CFCR 12917 (ESA, SPF); Pirani et al. CFCR 12544 (ESA, SPF).

Ocorre em áreas de cerrado e campos rupestres nos Estados de Goiás, Bahia e Minas Gerais. Em Grão-Mogol ocorre em beira de estradas e cerrados de solos arenosos. Foi coletada em flor nos meses de maio, junho, setembro e dezembro.

\section{Buchnera L.}

Ervas ou raramente subarbustos, freqüentemente referidos como hemiparasitas, geralmente glabros a híspido-escabros. Folhas opostas, raramente alternas ou verticiladas, sésseis, lineares a lanceoladas, menos freqüentemente elípticas, com nervuras geralmente paralelas, margem inteira a serreada. Flores dispostas em espigas terminais; bráctea (1) e bractéolas (2) inseridas junto ao cálice; cálice pentâmero, gamossépalo, cilíndrico; corola azul a arroxeada ou lilás, raramente alva ou vermelha, pentâmera, hipocraterimorfa; estames 4, inclusos, inseridos no tubo da corola, anteras monotecas; ovário pluriovulado. Fruto cápsula loculicida. Sementes trigonais a oblatas, com testa reticulada.

\subsection{Buchnera lavandulacea Cham. \& Schltdl., Linnaea 2: 589. 1827.}

Ervas a subarbustos, $0,4-1,8 \mathrm{~cm}$ alt., eretos ou suberetos; ramos glabros; internós 1,8-5,0 cm compr. Folhas opostas ou subopostas, linear-lanceoladas, 3,5-11,4 cm compr., 0,15-0,4 cm larg., ápice agudo, base decorrente no ramo, 3-5 nérveas, híspido-escabras nas nervuras e margens ou subglabras. Espigas 4,0-9,3 cm compr.; brácteas ovais ou lanceoladas, 0,15-0,3 cm compr., 0,1-0,25 cm larg., ápice agudo, ciliadas; bractéolas lanceoladas, 0,2 cm compr., 0,1 cm larg., ápice agudo, ciliadas. Flores lilases, opostas, cálice glabro, tubo 0,4-0,6 cm compr., lacínios triangulares, 0,1-0,15 cm compr.; tubo da corola $0,7-0,8 \mathrm{~cm}$ compr, lobos obovais a orbiculares, 0,2-0,4 cm compr. Cápsula elipsóide, 0,6-0,7 cm compr., 0,3-0,4 cm diâm. (Fig. 1. E-F)
Cordeiro \& Mello-Silva CFCR 10020 (ESA, SPF); Giulietti et al. CFCR 3484 (SPF); Mello-Silva \& Cordeiro CFCR 10028 (ESA, SPF); Oliveira et al. CFCR 13199 (ESA, SPF); Pirani et al. CFCR 8516 (ESA, SPF); Simão-Bianchini et al. CFCR 12871 (SPF); Simão-Bianchini et al. CFCR 13046 (ESA, SPF).

Ocorre em locais úmidos de campos rupestres e cerrados do Brasil Central. Em Grão-Mogol ocorre em campos arenosos com afloramentos rochosos, campos limpos e cerrados. Foi coletada em flor em maio, junho e setembro.

2.2. Buchnera palustris (Aubl.) Spreng., Syst. veg. 2: 805. 1825.

Ervas, 0,4-0,5 cm alt., eretas; ramos glabros; internós 0,9-2,0 cm compr. Folhas opostas a subopostas, lineares, 


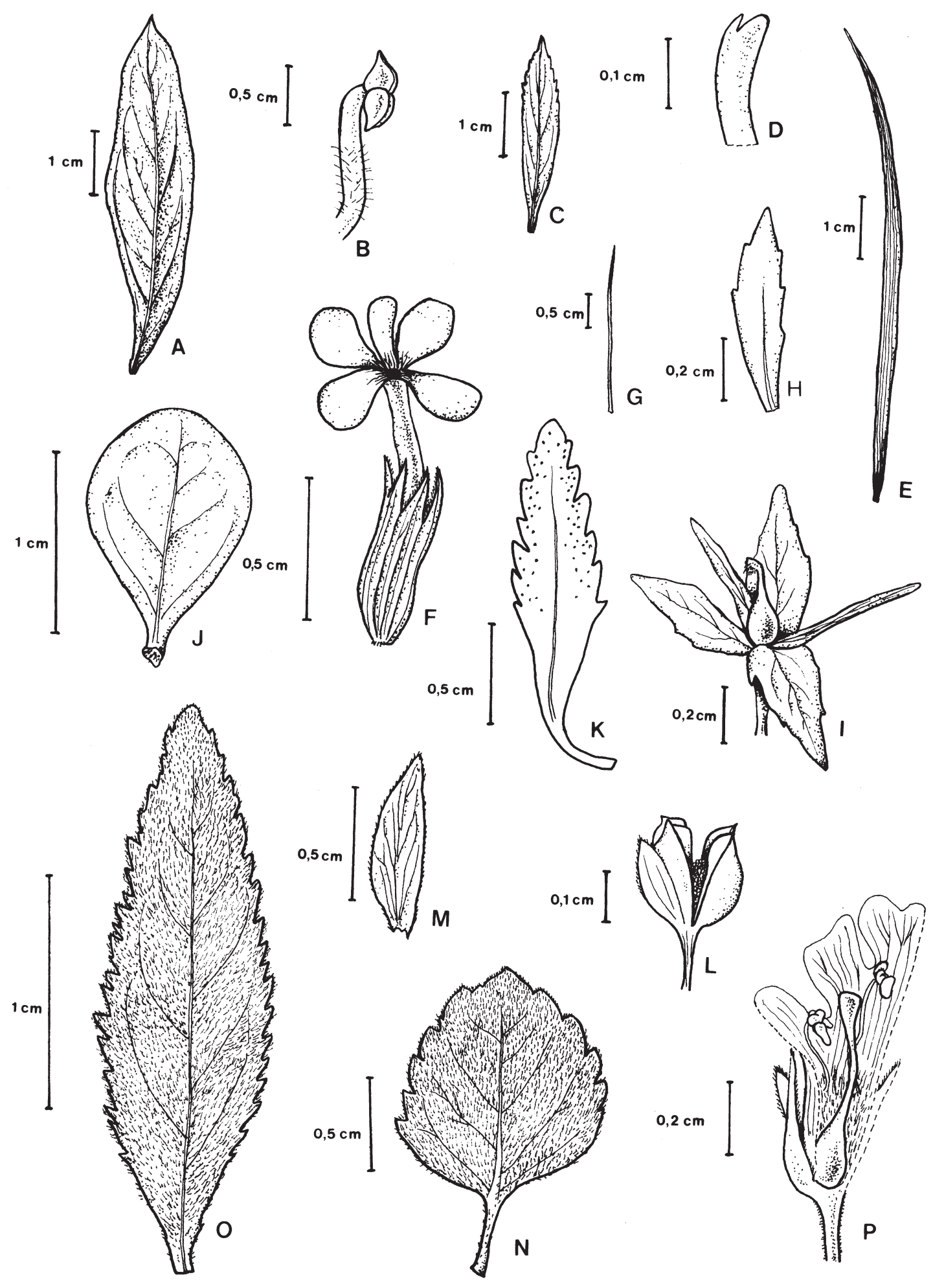

Fig. 1. SCROPHULARIACEAE. A-B: Angelonia eriostachys Benth. - A: Folha (Pirani \& Mello-Silva CFCR 10780); B: Estame (Campos et al. CFCR 13422). C-D: A. goyazensis Benth. - C: Folha; D: Apêndice da corola (Pirani et al. CFCR 12554). E-F: Buchnera lavandulacea Cham. \& Schltdl. - E: Folha (Simão-Bianchini et al. CFCR 12871); Flor (Simão-Bianchini et al. CFCR 13046). G: B. palustris (Aubl.) Spreng. - Folha (Simão-Bianchini et al. CFCR 13056). H-I: Mecardonia serpylloides (Cham. \& Schltdl.) Pennell - H: Folha; I: Cálice e gineceu (Menezes et al. 10179). J: Physocalyx aurantiacus Pohl - Folha (Cordeiro et al. CFCR 954). K-L: Scoparia dulcis L. - K: Folha; L: Fruto (Zappi et al. CFCR 12945). M-N: Stemodia microphylla J.A.Schmidt - M: Sépala; N: Folha (Pirani et al. CFCR 13431). O-P: S. pratensis (Aubl.) C.P.Cowan - O: Folha; P: Corte longitudinal da flor (Mamede et al. CFCR 3514). 
1,0-4,5 cm compr., ca. 0,1 cm larg., ápice agudo, base decorrente no pecíolo, uninérveas, híspido-escabras. Espigas 5,4-10,1 cm compr.; brácteas lanceoladas, 0,4-0,5 cm compr., 0,1-0,15 cm larg., ápice agudo, ciliadas; bractéolas lanceoladas, 0,4 cm compr., 0,1 cm larg., ápice agudo, ciliadas. Flores lilases, alternas, cálice glabro, tubo 0,5-0,7 cm compr., lacínios triangulares, 0,1-0,2 cm compr.; tubo da corola $0,7 \mathrm{~cm}$ compr., lobos orbiculares, $0,2-0,3 \mathrm{~cm}$ compr. Fruto não visto. (Fig. 1G).

$$
\text { Simão-Bianchini et al. CFCR } 13056 \text { (ESA, SPF). }
$$

Ocorre em campos úmidos desde a Venezuela e Guianas até o Brasil Central. Em Grão-Mogol ocorre em solo arenoso-humoso úmido, graminoso. Foi coletada em flor no mês de abril.

\section{Mecardonia Ruiz \& Pav}

Ervas glabras a pubescentes. Folhas opostas, sésseis a curtamente pecioladas, lineares, elípticas, lanceoladas, ovais a obovais, margem geralmente serreada. Flores axilares, solitárias, pediceladas; bractéolas geralmente presentes; cálice pentâmero, dialissépalo, sépalas desiguais, sendo a sépala dorsal mais larga que as sépalas ventrais, que por sua vez são mais largas que as medianas; corola amarela, pentâmera, bilabiada; estames 4, inclusos, inseridos no tubo da corola, anteras com tecas estipitadas, estaminódio raramente presente; ovário pluriovulado. Fruto cápsula septicida. Sementes elipsóides a ovóides, testa reticulada a cristado-reticulada.

3.1. Mecardonia serpylloides (Cham. \& Schltdl.) Pennell, Proc. Acad. Nat. Sci. Philadelphia 98: 87. 1946.

Ervas prostradas; ramos glabros, quadrangulares; internós $0,15-1,1 \mathrm{~cm}$ compr. Folhas opostas, sésseis a curtamente pecioladas, lanceoladas a elípticas, 0,4-1,1 cm compr., 0,1$0,3 \mathrm{~cm}$ larg., ápice agudo, margem serreada, glabras em ambas as faces. Flores sésseis, pedicelo até $0,6 \mathrm{~cm}$ na frutificação; bractéolas 2, inseridas junto ao cálice, lanceoladas, 0,25 $\mathrm{cm}$ compr., 0,1 cm larg., ápice agudo. Sépala dorsal oval a oval-lanceolada, 0,4-0,45 cm compr., 0,2-0,25 cm larg., ápice acuminado, ventrais oval-lanceoladas, 0,35-0,4 cm compr., ca. 0,15 cm larg., ápice agudo, laterais linear-lanceoladas, 0,35-0,4 cm compr., ca. 0,05 cm larg.; corola amarela, tubo 0,4-0,5 cm compr., lobos obovais, ca. $0,1 \mathrm{~cm}$ compr. Cápsula ovóide, 0,4 cm compr., 0,3 cm diâm. (Fig. 1.H-I)

Menezes et al. CFCR 10179 (SPF).

Ocorre em áreas abertas e úmidas desde Goiás e Minas Gerais até o Rio Grande do Sul. Em Grão-Mogol ocorre na margem de rios. Foi coletada em flor no mês de setembro.

\section{Physocalyx Pohl}

Subarbustos a arbustos, provavelmente hemiparasitas, glabros a híspido-escabros. Folhas opostas, raramente alternas ou verticiladas, sésseis a subsésseis, geralmente ovais, orbiculares ou obovais, margem inteira. Flores dispostas em racemos ou axilares solitárias concentradas nas terminações dos ramos, pediceladas; bractéolas presentes; cálice alaranjado, raramente verde-alaranjado, pentâmero, gamossépalo, ovóide, cilíndrico ou cupuliforme; corola alaranjada, pentâmera, cilíndrica; estames 4, inclusos, inseridos no tubo da corola, anteras com tecas paralelas, ligeiramente oblíquas; ovário pluriovulado. Fruto cápsula loculicida. Sementes lineares, com testa levemente reticulada.

4.1. Physocalyx aurantiacus Pohl, Pl. bras. icon. descr. 1: 65. 1827.

Ervas a subarbustos $0,7-0,8 \mathrm{~m}$ alt.; ramos glabros; internós $0,5-0,8 \mathrm{~cm}$ compr. Folhas opostas, elípticas, orbiculares ou obovais, 0,9-1,6 cm compr., 0,6-1,3 cm larg., ápice arredondado, margem inteira, base arredondada, obtusa ou aguda, glabras em ambas as faces. Flores axilares, solitárias, concentradas nas terminações dos ramos, formando um racemo não bem definido; pedicelo 1,5-2,0 cm compr., pubérulo; bractéolas oblanceoladas a obovais, 0,5-0,6 cm compr., 0,2-0,3 cm larg., ápice acuminado. Cálice alaranjado, ovóide, tubo 1,3 cm compr., lacínios triangulares, $0,35 \mathrm{~cm}$ compr.; tubo da corola 2,0 cm compr., lobos orbiculares, $0,2 \mathrm{~cm}$ compr. Cápsula ovóide, 1,0-1,3 cm compr., 0,6 cm diâm. (Fig. 1.J)

Cordeiro et al. CFCR 954 (ESA, SPF); Esteves et al. CFCR 13528 (ESA, SPF); Mamede et al. CFCR 3472 (ESA, SPF); Pirani \& MelloSilva CFCR 10820 (ESA, SPF).

Ocorre em campos rupestres da Cadeia do Espinhaço em Minas Gerais. Em Grão-Mogol ocorre em campo rupestre graminoso. Foi coletada em flor durante os meses de abril, maio e setembro. 


\section{Scoparia L.}

Ervas ou menos freqüentemente subarbustos, glabros, raramente pubescentes. Folhas opostas, raramente verticiladas, lineares a lanceoladas ou elípticas, freqüentemente pinatissectas, margem serreada ou menos freqüentemente inteira. Flores axilares, solitárias a fasciculadas, pediceladas; bractéolas ausentes; cálice tetrâmero ou pentâmero, dialissépalo, com sépalas iguais entre si; corola alva, rósea, azul, violácea ou amarela, tetrâmera, rotácea; estames 4 , exsertos, inseridos no tubo da corola, anteras com tecas paralelas; ovário pluriovulado. Fruto cápsula septicida. Sementes de formato variável, com testa reticulada.

\subsection{Scoparia dulcis L., Sp. pl.: 116. 1753.}

Ervas 25-100 cm alt.; ramos glabros ou esparsamente pubérulos; internós 1,0-2,7 cm compr. Folhas 3-verticiladas ou opostas, elípticas a lanceoladas, 1,1-1,8 cm compr., 0,2-0,5 $\mathrm{cm}$ larg., ápice agudo, margem serreada, base longamente atenuada, glanduloso-pontuadas. Flores alvas a arroxeadas, solitárias; pedicelo 0,4-0,5 cm compr. Sépalas 4, elípticas a lanceoladas, 0,15-0,2 cm compr., ca. 0,1 cm larg., ápice arredondado, ciliadas; corola vilosa internamente próximo à base, lobos elípticos, 0,2 cm compr. 0,15 cm larg. Cápsula ovóide, 0,2-0,3 cm compr, 0,2 cm diâm. (Fig. 1.K-L)

Zappi et al. CFCR 12945 (SPF).

Esta é uma das espécies mais comuns de Scrophulariaceae, ocorrendo em áreas abertas naturais ou como invasora de culturas. Em Grão-Mogol é encontrada entre rochas em carrascal com cerrado. Foi coletada em flor no mês de abril.

\section{Stemodia L.}

Ervas a subarbustos, raramente arbustos, com indumento bastante variável. Folhas opostas a verticiladas, sésseis a pecioladas, com formato e margem bastante variáveis. Flores axilares, solitárias ou fasciculadas, freqüentemente concentradas nas terminações dos ramos formando uma espiga não bem definida, sésseis a pediceladas; bractéolas presentes ou ausentes; cálice pentâmero, dialissépalo com lacínios iguais ou subiguais entre si; corola geralmente arroxeada a lilás, pentâmera, bilabiada; estames 4, inclusos ou exsertos, inseridos no tubo da corola, anteras com tecas estipitadas; estaminódio presente ou ausente; ovário pluriovulado. Fruto cápsula loculicida. Sementes de formato e testa bastante variáveis.

6.1. Stemodia microphylla J.A.Schmidt in Mart., Fl. bras. 8(1) 298: 1862.

Ervas prostradas, muito ramificadas; ramos densamente pubescentes; internós 0,6-1,7 cm compr. Folhas opostas; pecíolo 0,2-0,5 cm compr.; lâmina oval, 0,7-1,6 cm compr., 0,6-1,2 cm larg., ápice obtuso, margem serreada, base obtusa ou truncada, face superior pubescente, inferior pubescente principalmente nas nervuras. Flores axilares, solitárias; pedicelo 0,9-1,0 cm compr., pubescente; bractéolas opostas, lanceoladas, 0,3 cm compr., 0,1 cm larg., ápice agudo, ciliadas. Sépalas lanceoladas, 0,5-0,7 cm compr., 0,15-0,2 $\mathrm{cm}$ larg., pubescentes; tubo da corola amarelo, 0,7-0,8 cm compr., lobos róseos, suborbiculares, 0,2-0,3 cm compr. Fruto elipsóide, 0,3 cm compr., 0,25 cm larg. (Fig. 1.M-N)

Pirani et al. CFCR 13431 (ESA, SPF).

Ocorre nos campos rupestres de Minas Gerais. Em GrãoMogol ocorre em fendas de rochas à sombra. Foi coletada em flor em setembro.

6.2. Stemodia pratensis (Aubl.) C.P.Cowan, Phytologia 75(4): 309. 1993.
Ervas a subarbustos $0,5-1,5 \mathrm{~m}$ alt., eretas; ramos pubescentes; internós 1,3-5,0 cm compr. Folhas opostas, sésseis ou com pecíolo até $0,1 \mathrm{~cm}$ compr, lanceoladas, 1,4-4,7 cm compr., 0,5-1,2 cm larg., ápice agudo, margem serreada, base aguda ou atenuada, pubescentes a densamente pubescentes em ambas as faces. Flores solitárias ou em feixes de 2-3; pedicelo 0,3-0,4 cm compr., com indumento semelhante ao dos ramos; bractéolas ausentes. Sépalas lanceoladas, 0,4 cm compr., 0,1 cm larg., ápice agudo, com indumento semelhante ao dos ramos; corola lilás, tubo $0,5-0,7 \mathrm{~cm}$ compr., lobos oboval-obtriangulares, 0,2-0,3 cm compr. Cápsula ovóide, 0,3 cm compr., 0,2 cm diâm. (Fig. 1.O-P)

Hatschbach 41228 (MBM); Mamede et al. CFCR 3514 (ESA, SPF); Pirani \& Mello-Silva CFCR 10849 (ESA, SPF); Zappi et al. CFCR 9877 (ESA, SPF).

Ocorre desde o Nordeste o Brasil até Minas Gerais, tendo sido também coletada no litoral de São Paulo e na Venezuela e Guianas. Em Grão-Mogol ocorre em campos graminosos com solos arenosos, locais de escoamento de água e margem de estradas. Foi coletada em flor nos meses de abril, maio e julho. 
